\title{
Response by women aged 65-79 to invitation for screening for breast cancer by mammography: a pilot study
}

\author{
P Hobbs, C Kay, E H I Friedman, A S St Leger, C Lambert, C R M Boggis, T M Howard, \\ D L Asbury
}

Regional Oncology Support Service, North West Regional Health Authority, Manchester M20 9QL P Hobbs, PHD, director C Lambert, BA, services officer

Barlow Medical Centre, Manchester

C Kay, CBE, FRCGP, general practitioner

Manchester Breast Screening Service, Manchester

E H I Friedman, MFPHM, manager

T M Howard, DCR(R), superintendent radiographer D L Asbury, FRCR, clinical director of breast screening

Withington Hospital, Manchester

C R M Boggis, FRCR, consultant radiologist

South Manchester Health Authority, Manchester

A S St Leger, FFPHM, consultant in public health medicine

Correspondence to: $\mathrm{Dr}$ Hobbs.

\begin{abstract}
Objective-To determine whether there is sufficient benefit to be gained by offering screening for breast cancer with mammography to women aged 65-79, who are not normally invited for screening.

Design-Pilot study of women eligible for screening but not for personal invitation. The results of this study were compared with the results of routinely screened younger women (aged 50-64) from the same general practice.
\end{abstract}

Setting-One group general practice in south Manchester.

Patients-The 631 women aged 65-79 on the practice list. A total of $42(7 \%)$ were excluded by the general practitioner, and $22(4 \%)$ invitation letters were returned by the post office.

Main outcome measures-Response rates to invitation for screening assessed by three indices: crude population coverage ratio, crude invited population coverage ratio, and corrected invited population coverage ratio.

Results-344 Patients aged 65-79 (61\% of those invited, excluding those who could not be traced) were screened compared with $77 \%$ of women aged 50-64. The three response indices were higher for younger women than older: crude population coverage ratio $=66.5 \%$, crude invited population coverage ratio $=69.3 \%$, corrected invited population coverage ratio $=\mathbf{7 6} \cdot 8 \%$ for women aged $50-64$, compared with $54.5 \%, 58.4 \%$, and $\mathbf{6 0 . 7 \%}$ respectively for women aged 65-79. All four biopsies done in the older women gave positive results, giving a cancer detection rate of $11 \cdot 6 / 1000$ compared with $4 \cdot 1 / 1000$ among younger women.

Conclusions - These results show that there is a potential for high attendance at routine screening by older women if they are invited in the same way as younger women. If these results are found elswhere the costs and benefits of screening older women should be reassessed.

\section{Introduction}

Breast cancer screening programmes using mammography in the United Kingdom are funded in the expectation that they adhere to the proposals in the Forrest report.' These include triennial screening by invitation of women aged 50-64 and screening of older women on demand. Older women are excluded from routine call and recall mainly because it is thought that their response to invitation would be low and the expected benefit would not justify the effort. These proposals seem to have been based on assumptions about both the United Kingdom trial, ${ }^{2}$ which had not yet been reported ${ }^{3}$ and was confined to women aged 50-64 at the onset of screening, and the Nijmegen (Netherlands) study, ${ }^{4}$ which showed 70 to be the age of appreciable reduction in initial response and rescreening. Additional reasons for not inviting older women were that they have an increased chance of dying of other diseases and that "breast cancer diagnosed in older women appears to run a less aggressive course than when diagnosed in younger women." Nevertheless, evidence from the two counties (Swedish) study showed acceptance of over $80 \%$ (51 064 of 58148 ) and a reduction in mortality from breast cancer in women up to the age of $74 .^{5}$ We believe that the potential response and benefits of screening older women have been dismissed too readily.

South Manchester Health Authority has operated a Forrest style screening service for the city of Manchester since June 1988. It has caused considerable interest among women of all ages, but during one year, when 7168 women (aged 50-64) attended from routinely called batches, only 133 older women referred themselves. This statistic, however, cannot be taken as evidence that older women would not attend in adequate numbers if invited and subjected to the same health education as younger women. To study the matter further we carried out a pilot study by formally inviting older women for screening.

\section{Patients and methods}

The population potentially eligible for screening consisted of the 631 women aged from 65 to 79 on the list of one group general practice in south Manchester.

As with the Forrest programme, a prior notification list was constructed from the practice list held by the Manchester Family Practitioner Committee. The checking of the prior notification list for accuracy, which was normally undertaken by staff of the practice, was carried out by a researcher (CL), who also did a preliminary check for potential ineligibility and then passed the records to the general practitioners for final decisions. Names and addresses from the corrected list were entered in to our screening office computer system (Oxford) and constituted as a normal screening batch.

Invitation letters giving appointments for screening, a reply paid card, a leaflet, a general practitioner's support letter, and a map were sent to these women in the normal way. There were only three differences.

Firstly, the invitation (from the breast screening service manager, EHIF) and the general practitioner's support letter explained that earlier in the year women aged 50-64 had been invited for screening and that most of them had come. "Now we are able to arrange for women aged 65 and over to be screened during the month of August at the new Nightingale Centre at Withington Hospital. We strongly recommend that you take the opportunity to attend for this simple test." (This was taken from the doctors' support letter signed by all partners in the practice, which was otherwise the same as that sent to younger women.) 
Secondly, a new map of the hospital was produced showing the use of the former hospital chapel as the Nightingale breast screening unit, but the centre was not identified and the maps were therefore of little help. Fortunately, the invitation letter did explain the centre's location on the hospital site, and once the error was noticed the hospital's lodge staff were made aware of the problem.

Thirdly, the Nightingale Centre was used whereas the younger women were screened in a mobile unit on the hospital site, which later moved to other sites.

All appointments were made for special screening sessions during August 1989, when the main screening programme was in summer recess. As with younger women, these older clients had the opportunity to change their appointments by telephone or reply paid card.

The mammographic procedures were identical with those used with younger women. Women with inadequate mammograms or suspicious mammographic findings were recalled for repeat mammography or assessment in the normal way.

Three statistical ratios were calculated from the data to allow the coverage and uptake of screening by older women to be compared with those by younger women. (1) The crude population coverage ratio is the ratio of the number of women screened to the number on the prior (uncorrected) notification list. It is a measure of the true population coverage assuming that family practitioner committee records are accurate. (2) The crude invited population coverage ratio is the ratio of the number of women screened to the number invited for screening. It is a measure of the overall ability of the service to capture women believed to be in its catch-

TABLE I-Results of routine screening of younger women and pilot study of older women from one general practice by age. Figures are numbers (percentages) of women

\begin{tabular}{|c|c|c|c|c|c|}
\hline Age (years) & $\begin{array}{c}\text { No on prior } \\
\text { notification list }\end{array}$ & $\begin{array}{l}\text { No ceased or } \\
\text { excluded }\end{array}$ & No invited & $\begin{array}{l}\text { Letters returned } \\
\text { by post office }\end{array}$ & $\begin{array}{l}\text { No screened } \\
\text { (crude population } \\
\text { coverage ratio) }\end{array}$ \\
\hline \multicolumn{6}{|c|}{ Routine screening } \\
\hline $50-$ & $253(100 \cdot 0)$ & $8(3 \cdot 2)$ & $245(96 \cdot 8)$ & $28(11 \cdot 4)$ & $165(65 \cdot 2)$ \\
\hline $55-$ & $224(100 \cdot 0)$ & $9(4 \cdot 0)$ & $215(96 \cdot 0)$ & $25(11 \cdot 6)$ & $146(65 \cdot 2)$ \\
\hline $60-64$ & $261(100 \cdot 0)$ & $12(4 \cdot 6)$ & $249(95 \cdot 4)$ & $17(6.8)$ & $180(69 \cdot 0)$ \\
\hline Total & $738(100 \cdot 0)$ & $29(3.9)$ & $709(96 \cdot 1)$ & $70(9 \cdot 5)$ & $491(66 \cdot 5)$ \\
\hline \multicolumn{6}{|c|}{ Pilot study } \\
\hline $65-$ & $216(100 \cdot 0)$ & $15(6.9)$ & $201(93 \cdot 1)$ & $13(6 \cdot 5)$ & $125(57 \cdot 9)$ \\
\hline 70- & $212(100 \cdot 0)$ & $18(8 \cdot 5)$ & $194(91.5)$ & $4(2 \cdot 1)$ & $111(52 \cdot 4)$ \\
\hline $75-79$ & $203(100 \cdot 0)$ & $9(4 \cdot 4)$ & $194(95 \cdot 6)$ & $5(2 \cdot 6)$ & $108(53 \cdot 2)$ \\
\hline Total & $631(100 \cdot 0)$ & $42(6 \cdot 7)$ & $589(93 \cdot 3)$ & $22(3 \cdot 5)$ & $344(54 \cdot 5)$ \\
\hline \multicolumn{6}{|c|}{ Overall } \\
\hline $50-79$ & $1369(100 \cdot 0)$ & $71(5 \cdot 2)$ & $1298(94 \cdot 8)$ & $92(6 \cdot 7)$ & $835(61 \cdot 0)$ \\
\hline
\end{tabular}

Percentages in columns 3, 4, and 6 are of column 2; in column 5 of column 4

TABLE II - Distribution and uptake of screening of women by age

\begin{tabular}{lccc}
\hline Age (years) & $\begin{array}{c}\text { Crude population coverage } \\
\text { ratio }(\%)\end{array}$ & $\begin{array}{c}\text { Crude invited population } \\
\text { coverage ratio }(\%)\end{array}$ & $\begin{array}{c}\text { Corrected invited population } \\
\text { coverage ratio }(\%)\end{array}$ \\
\hline $50-$ & $165 / 253(65 \cdot 2)$ & $165 / 245(67 \cdot 3)$ & $165 / 217(76 \cdot 0)$ \\
$55-$ & $146 / 224(65 \cdot 2)$ & $146 / 215(67 \cdot 9)$ & $146 / 190(76 \cdot 8)$ \\
$60-64$ & $180 / 261(69 \cdot 0)$ & $180 / 249(72 \cdot 3)$ & $180 / 232(77 \cdot 6)$ \\
\hline Total & $491 / 738(66 \cdot 5)$ & $491 / 709(69 \cdot 3)$ & $491 / 639(76 \cdot 8)$ \\
\hline $65-$ & $125 / 216(57 \cdot 9)$ & $125 / 201(62 \cdot 2)$ & $125 / 188(66 \cdot 5)$ \\
$70-$ & $111 / 212(52 \cdot 4)$ & $111 / 194(57 \cdot 2)$ & $111 / 190(58 \cdot 4)$ \\
$75-79$ & $108 / 203(53 \cdot 2)$ & $108 / 194(55 \cdot 7)$ & $108 / 189(57 \cdot 1)$ \\
\hline Total & $344 / 631(54 \cdot 5)$ & $344 / 589(58 \cdot 4)$ & $344 / 567(60 \cdot 7)$ \\
\hline
\end{tabular}

TABLE III - Results of screening of younger and older women. Figures are number of women

\begin{tabular}{lccccc}
\hline Age (years) & No screened & $\begin{array}{c}\text { No who needed } \\
\text { surgical opinion }\end{array}$ & $\begin{array}{c}\text { No who needed } \\
\text { biopsy }\end{array}$ & No with cancer & Size of lesion \\
\hline $50-64$ & 491 & 4 & 3 & 2 & $<10 \mathrm{~mm}(1)$ \\
$65-79$ & 344 & 4 & 4 & 4 & $25 \mathrm{~mm}(1)$ \\
& & & & & $10 \mathrm{~mm}(2)$ \\
& & & & & \\
\hline
\end{tabular}

ment area and known to be eligible for screening. (3) The corrected invited population coverage ratio is the ratio of the number of women screened to the number believed to have received invitation letters - that is, post office returned letters are excluded from the denominator. This is a measure of the ability of the service to persuade identified women to attend for screening.

\section{Results}

Table I shows the histories of the routinely screened younger women and the study group of older women taken from the same general practice. Of 738 younger women, $29(4 \%)$ were excluded from the invitation list by their general practitioners, and of 631 older women, $42(7 \%)$ were excluded. Most of the older women were excluded on medical grounds. The proportions of invitation letters returned by the post office (that is, the putative recipient was not traced) were $10 \%$ and $4 \%$ respectively for younger and older women.

Table II shows three coverage and uptake statistics calculated from the data in table I. Overall the three indices were higher for younger women than older women. Nevertheless, for older women all indices were greater than $50 \%$. There was no clear trend with age in these indices among the younger women. There was an appreciable decrease in all three indices for women aged 65-69, however, and a further appreciable decrease for women aged 70-74.

For comparison, during the first year of screening in the city of Manchester the overall crude population coverage ratio, crude invited population coverage ratio, and corrected invited population coverage ratio for routinely invited women aged 50-64 were $60 \cdot 9 \%$, $65 \cdot 7 \%$, and $72 \cdot 3 \%$ respectively.

The screening results given in table III show that there were no negative findings on biopsy in the older women. The rate of breast cancers detected, $11 \cdot 6 / 1000$, was much higher than the $4 \cdot 1 / 1000$ in the younger women, and the size of the lesions was comparable.

\section{Discussion}

The difference in the proportions of letters returned by the post office for older $(4 \%)$ and younger $(10 \%)$ women may reflect a more static older population. Most of the women were excluded from the initial notification list because of medical grounds rather than the discovery that they should no longer be on the practice list. This is perhaps not surprising.

The coverage and uptake statistics among younger women from this general practice were several percentage points better than those for the overall Manchester programme in its first year. This raises the question of whether our pilot study has used an unusual general practice and hence increased the response among older women. In some respects the practice is atypical because it covers a reasonably affluent part of Manchester; also, the general practitioners have a keen interest in population screening and research. Nevertheless, the comparison between the younger and older women from this practice remains valid. Anecdotal evidence gathered by the radiographers from their clients suggests that the older women hold their doctors in high esteem and were greatly influenced by their letters of support. Unless specifically approached by these women, however, the family practitioners did not try to promote high attendance through personal contact with patients.

Two factors might have militated against participation. One, related to availability to be screened, was confining the programme to August; elderly people are not usually constrained about when to take holidays 
but may have joined younger family members. The other was the inaccuracy of the map, which might have discouraged some women, particularly those for whom walking was difficult.

Nevertheless, this exercise resulted in 344 women aged 65-79 being screened. During the first year of the screening programme only 133 women aged 65 and over in the whole city had referred themselves for screening and only 10 of those came from this practice.

The greater cancer detection rate from screening the older women $(11 \cdot 6 / 1000$ as compared with $4 \cdot 1 / 1000$ in the younger women of the practice) may be associated with the higher incidence of breast cancer ${ }^{1}$ but, given that mortality from the disease also increases with age, is not to be disregarded. It also means that a lower response rate in these older women is still acceptably productive. As these women had not sought screening at the time that the younger women were invited, these cancers probably would not have been found before the patients showed symptoms if the invitations had not been issued.

It is clear from published reports and from this study that older women respond less well than younger ones to invitations to screening. How do we define older and younger? The Swedish study showed a decline in response from $88 \%$ for patients aged $60-69$ to $79 \%$ for those aged 70-74 at first screening. ${ }^{5}$ In Holland the drop was from $80 \%$ among those aged $60-69$ to $35 \%$ among those aged 70 and over. ${ }^{+}$Our study also showed an appreciable fall at age 70 from $73 \%$ at age $60-69$ to $58 \%$ at age 70-79. The Health Insurance Plan study, ${ }^{6}$ however, was able to show effectiveness on a $65 \%$ first screening level at the age of 40-64 (though only in those aged 50 and over), and the United Kingdom trial ${ }^{3}$ had a response of $66 \%$ on a first screen (age 45-64), though this may not have been a corrected invited population coverage ratio. With a higher incidence of disease in older women a $58 \%$ response rate can still give a good return for the effort expended.

Although we must not be complacent, the initial results from Manchester as a whole and this practice in particular suggest that the invitation "package" and the running of the programme at every level are "user friendly." Much of the planning was based on the "COSI" principles (consumer oriented, service initiated) described elsewhere ${ }^{8}$ and arising partly from experience in the Manchester Department of Health and Social Security phase I feasibility study. Although the classical picture of women's response to screening opportunities shows bias towards women who are younger, better educated, of higher social class, and with higher incomes, most of the reports on which that view is based are concerned with programmes made available to women, which leave them to take the initiative. A well designed personal invitation system can reduce the effects of age, at least up to 70 , and eliminate the effect of social class."

By applying the above principles to these older women we increased the numbers screened from 10 to $344-$ a result which is remarkable. We have shown that there is a potential for high attendance at routine screening by older women if they are invited in the same way as younger women. Clearly, our study should be replicated elsewhere. If our findings are duplicated then the economics (impact on the population $v$ cost) of extending routine call and recall screening to elderly women must be reassessed.

1 Forrest P. Breast screening. Report to the health ministers of England, Wales, Scotland, and Northern Ireland by a working group chaired by P Forrest. London: HMSO, 1986.

2 UK trial of early detection of breast cancer group. Trial of early detection of breast cancer: description of method. Br 7 Cancer 1981;44:618-27.

3 UK trial of early detection of breast cancer group. First results on mortality reduction in the UK trial of early detection of breast cancer. Lancet reduction in

4 Verbeek ALM, Hendriks JHCL, Holland R, Mravunac M, Sturmans F, Da NE. Reduction in breast cancer mortality through mass screening with modern mammography. (First results of the Nijmegen project, 1975-1981). Lancet $1984 ; \mathrm{i}: 1222-4$

5 Tabar L, Fagerberg CJG, Gad A, et al. Reduction in mortality from breas cancer after mass screening with mammography. Lancet 1985; ;:829-32

6 Shapiro S. Evidence on screening for breast cancer from a randomised trial. Cancer 1977:39:2772-82.

7 Shapiro S, Venet W, Strax P, Venet L, Roeser R. Ten to fourteen-year effect of screening on breast cancer mortality. FNCI 1982;69:349-55.

8 Hobbs P, Elkind AK, Haran D, et al. Screening for cervical cancer: an opportunity for change. In: Smith A, ed Recent Advances in Community opportunity for change
Medicine 1984;3:249-68.

9 Hobbs P, Smith A, George WD, Sellwood RA. Acceptors and rejectors of an invitation to undergo breast screening compared with those who referred themselves. F Epidemiol Community Health 1980;34:19-22.

(Accepted 14 September 1990)

\section{Correction}

Effect of a general practitioner's consulting style on patients' satisfaction

An authors' error occurred in this article by Drs Richard Savage and David Armstrong (27 October, pp 968-70). Reference 4 should read Thomas KB. General practice consultations: Is there any point in being positive? BMF 1987;294:1200-2

\section{MIRROR OF MEDICINE}

In the' debate on the motion Mr Lord of Hampstead called the Fournal "effete... stale, flat and unprofitable"; the question which faced the meeting, he averred, was "whether they would continue to have a journal supplied to them, backward in intelligence and torpid in delivery, or such an efficient organ as that proposed by Dr Cowan." Thomas Nunneley of Leeds then took up the Council's suggestion that a committee be appointed to consider the question. A show of hands on Nunneley's amendment yielded an indecisive result. Accordingly, members were requested to move to the left or right of the chair depending on whether they supported or rejected the amendment. The undecided were asked to clear the room. Of the 120 members who stayed, 61 voted for the amendment. The announcement of this result "was received with much applause, and an exciting scene ensued, and in the midst of the confusion attendant on this, the President declared the original motion (which had not been formally put to the meeting) carried" [emphasis in original]. What happened next is unclear. Cowan signified his acceptance of the committee nominated by Nunneley and moved for its appointment with an instruction that it superintend future fournal production in London. But most of those whom Nunneley had nominated withdrew their names. According to the fournal's account, compiled by a Council reporter, "a Committee consisting of eight or nine gentlemen was understood to be appointed, though the proceedings here were extremely confused, and the appointment, if made at all, was done in a most irregular manner."

Cowan, who was appointed chairman of the new committee, assured Ranking and Walsh that they might remain as editors for the remainder of the year, but Ranking had had enough and resigned. Walsh was inclined to do likewise but, fearing that the fournal might be irreparably damaged by the sudden departure of both editors, agreed to stay on. During August and September Walsh, in a series of editorials, sought to establish that nothing had been achieved at the Oxford meeting because Cowan had given insufficient notice of his motion and because the chairman had followed incorrect procedure. But, at a meeting held in September, Council "having ascertained from many influential members of the Association, that the general feeling is in favour of the validity of the resolution passed at Oxford, with regard to the fournal, are of opinion that it is not desirable further to insist upon the informality of Dr. Cowan's proposition."

From Mirror of Medicine: A History of the BMF by P W J Bartrip. Published jointly by the $B M F$ and Oxford University Press; BMA members' price UK $£ 29$, overseas $£ 33$, including postage. Obtainable from the Publishing Manager, $B M 7$, PO Box 295, London WC1H 9TE. Non-members UK £35. Obtainable from OUP Distribution Services, Saxon Way West, Corby, Northamptonshire NN189ES 